\title{
RADIAL FLOW MODELING FOR ESTIMATING \\ LEVEL-BASIN IRRIGATION PARAMETERS
}

by

E. Playán, ${ }^{1}$ Assoc. Member ASCE, and P. García-Navarro, ${ }^{2}$ Assoc. Member ASCE

\section{SUMMARY :}

A radial flow simulation model was applied to the estimation of infiltration and roughness parameters of point-inflow level-basin irrigation events. It was concluded that the estimation of such parameters is at least as possible for radial flow as it is for parallel flow.

\section{KEYWORDS :}

Inverse problem, level-basin, polar coordinates, shallow water, finite differences, explicit, source terms.

\begin{abstract}
:
Previous research in the estimation of surface irrigation parameters from advance time or surface profile observations has focused on the development of solutions for parallel surface flow conditions. This study was conducted to assess the usefulness of a polar model simulating radial flow in the

\footnotetext{
${ }^{1}$ Res., Dept. Genética y Producción Vegetal, Laboratorio de Agronomía y Medio Ambiente CSIC-DGA, Estación Experimental de Aula Dei (CSIC). Apdo. 202, 50080 Zaragoza, Spain. Email : playan@eead.csic.es
}

${ }^{2}$ Assoc. Prof., Área de Mecánica de Fluidos, CPS, Universidad de Zaragoza. María de Luna, 3 ACTUR. 50015 Zaragoza, Spain. Email : pigar@posta.unizar.es 
estimation of infiltration and roughness parameters of a point-inflow level-basin irrigation event. The two-step explicit McCormack scheme was applied to the solution of the governing equations. The method of characteristics was used at boundary nodes. Point-wise semi-implicit discretization of the friction and geometric source terms was used. Results of this model compared well with those obtained with a two-dimensional cartesian model simulating radial flow. Gradient and non-gradient minimization techniques were applied to determine pairs of infiltration and roughness parameters. The estimation of the parameters is as feasible for radial flow as it is for parallel flow.

\section{INTRODUCTION}

In recent decades, a large effort has been devoted to the development of unsteady flow models adapted to different types of surface irrigation systems. These models have been successfully used for many purposes, including occasional applications to the design and management of surface irrigation systems. Numerical methods have been commonly used to predict discharge and water levels in surface irrigation systems. The shallow water equations, being a hyperbolic partial differential system, are a good candidate for the application of many of the numerical techniques developed in the field of Gas Dynamics for the Euler equations. Hydraulic models have been applied to the estimation of surface irrigation parameters, solving what has been called the inverse problem. Estimated parameters are the Manning roughness factor, $n$, and the parameters of a Kostiakov-Lewis infiltration equation $\left(k, a\right.$, and $\left.f_{0}\right)$. Inverse solution procedures assume that soil roughness, infiltration and field slope are uniform (Clemmens and Keats, 1992b).

Estimation procedures can be classified as predictive, which require multiple simulations of the irrigation event with a hydraulic model, and non predictive, which solve directly for the parameters based on volume balance principles and gross assumptions about the surface flow and infiltration profiles (Katopodes et al., 1990). In recent years, advances have been made in the solution of the inverse 
problem using both non-predictive and, particularly, predictive techniques. Katopodes (1990) analyzed the observability of surface irrigation advance using a zero-inertia model. He concluded that two parameters can be estimated from observations of an irrigation event that allow reconstruction of the surface profile. Three parameters can be estimated provided that the initial estimates fall within the radius of convergence of the 'real' values. Scaloppi et al. (1995) applied volume balance theory to estimate three infiltration parameters using advance and/or wetting data. Clemmens (1991) developed a direct procedure to solve the inverse problem based on a modification of the double-sweep step of a zero-inertia model. Clemmens and Keats (1992a, 1992b) used bayesian inference and a zero-inertia model to perform real-time estimation of $k$ and $a$ based on the advance curve and subjective estimates provided by the irrigator. Applications of the inverse problem concept to different irrigation systems are reported in Bautista and Wallender (1993), Hanson et al. (1993) and Valiantzas (1994).

If a uniform discharge is applied along one end of a rectangular field with uniform slope, infiltration and roughness, the problem remains one-dimensional independently of whether the modeling is done in a one- or a two-dimensional cartesian frame. In the present paper, this situation will be referred to as parallel flow. In cases such as level-basins irrigated from a point source, and assuming uniformity in infiltration, roughness and soil surface elevation, the flow can be said to be radial. In twodimensional polar coordinates, radial flow can be expressed as a one-dimensional problem.

Previous research in this area has focused on the estimation of parameters from the observation of surface irrigation events involving parallel surface flow. Under radial flow conditions the existing prediction schemes can not be applied. A two-dimensional Cartesian model is needed to solve this problem for different inflow configurations and field geometries. Often, estimation of the infiltration parameters is desired at the early stages of the irrigation event, when the flow is more likely to follow a radial pattern. In such cases, a Polar model could be advantageously applied as a predictive tool for parameter estimation. 
In the following section, the one- and two-dimensional shallow water equations will be presented in cartesian coordinates. The transformation of these equations to two-dimensional polar coordinates will be sketched. The polar equations will be simplified by assuming axial symmetry. New source terms appear as a consequence of the coordinate transformation. The scheme applied to discretize the onedimensional system of partial differential equations is the explicit finite difference McCormack scheme. The source terms are treated pointwise, meaning that they are evaluated at every nodal point, not decomposed in any upwind manner.

In the second part of this paper, the one-dimensional Cartesian and Polar models are coupled to minimization algorithms to obtain predictive inverse solutions for parallel and radial flow conditions. Numerical experiments are used to compare the performance of both solvers and determine their potential for level-basin irrigation parameter estimation.

\section{MATHEMATICAL MODELING}

\section{One-dimensional Cartesian model}

Unsteady flow of water in open channels can be described by the shallow water or St. Venant equations (Eqs. 1 and 2). In a one-dimensional approach, these equations express mass and momentum balance along the direction of the main flow (Cunge et al. 1980).

$$
\begin{gathered}
\frac{\partial A}{\partial t}+\frac{\partial Q}{\partial x}=-i(x, t) \\
\frac{\partial Q}{\partial t}+\frac{\partial}{\partial x}\left(\frac{Q^{2}}{A}+g_{1}\right)=g I_{2}+g A\left(S_{0}-S_{f}\right)+D_{i}
\end{gathered}
$$

where $A$ is the wetted cross sectional area, $Q$ is the unit discharge and $g$ is the acceleration due to gravity. $I_{1}$ represents a unit hydrostatic pressure force term 


$$
I_{1}=\int_{0}^{h(x, t)}(h-\eta) b(x, \eta) d \eta
$$

where $h$ is the total water depth at every location, $\eta$ is the variable water depth and $b$ (the cross-sectional width) can be expressed as:

$$
\mathrm{b}(\mathrm{x}, \eta)=\frac{\partial \mathrm{A}(\mathrm{x}, \eta)}{\partial \eta}
$$

Similarly, $I_{2}$ accounts for the unit pressure forces due to longitudinal width variations,

$$
I_{2}=\int_{0}^{h(x, t)}(h-\eta) \frac{\partial b(x, \eta)}{\partial x} d \eta
$$

All the one-dimensional cases analyzed in this work involve prismatic channels or furrows, so that the $I_{2}$ pressure term will not be used in what follows.

The right hand side of Eq. (2) contains the sources and sinks of momentum arising from the bed slope and the friction losses. The bed slope is the spatial partial derivative of the bottom elevation $z$,

$$
\mathrm{S}_{0}=-\frac{\partial \mathrm{z}}{\partial \mathrm{x}}
$$

The variable $S_{0}$ will not be of interest in this paper since level-basin irrigation is characterized by a zero slope and microtopography will not be considered. The friction slope is defined in terms of the Manning roughness coefficient $n$ :

$$
\mathrm{S}_{\mathrm{f}}=\frac{\mathrm{Q}|\mathrm{Q}| \mathrm{n}^{2}}{\mathrm{~A}^{2} \mathrm{R}^{\frac{4}{3}}}
$$

with $R=A / P, P$ being the wetted perimeter. Other forms of $S_{f}$ can equally well be used.

A lateral outflow due to the infiltration rate, $i$, can be computed using the empirical KostiakovLewis equation

$$
\mathrm{i}=\mathrm{ka} \tau^{\mathrm{a}-1}+\mathrm{f}_{0}
$$


where $\tau$ is the opportunity time measured in minutes and $k, a$ and $f_{0}$ are empirical parameters. The term $D_{i}$ accounts for the momentum transfer associated with seepage outflow in the direction of the flow and is evaluated here as :

$$
\mathrm{D}_{\mathrm{i}}=\frac{\mathrm{Q} \mathrm{i}}{2 \mathrm{~A}}
$$

The homogeneous version of Eqs. (1) and (2) is a system of conservation laws analogous, from the mathematical point of view, to the system of Euler equations. Some years after their adoption for solving problems in Gas Dynamics numerical schemes have been successfully used for the solution of the shallow water equations, with similar advantages (García-Navarro and Alcrudo, 1992).

\section{Two-Dimensional Cartesian Model}

The two-dimensional shallow water flow equations can be written in cartesian form as (Abbott, 1992) :

$$
\mathbf{U}=(\mathrm{h}, \mathrm{uh}, \mathrm{vh})^{\mathrm{T}}
$$

$h, u$ and $v$ are the depth and the velocities in the $x$ and $y$ directions respectively, are

$$
\frac{\partial \mathbf{U}}{\partial \mathrm{t}}+\frac{\partial \mathbf{E}}{\partial \mathrm{x}}+\frac{\partial \mathbf{F}}{\partial \mathrm{y}}=\mathbf{G}
$$

The fluxes in the second term of the equations are,

$$
\mathbf{E}=\left(\begin{array}{c}
u h \\
u^{2} h+\frac{g h^{2}}{2} \\
u v h
\end{array}\right), \quad \mathbf{F}=\left(\begin{array}{c}
\text { vh } \\
u v h \\
v^{2} h+\frac{g h^{2}}{2}
\end{array}\right)
$$

The speed of the surface perturbations on still water is the wave celerity, defined as $c=\sqrt{\mathrm{gh}}$. It is useful for the definition of the governing equations the dimensionless Froude number

$$
\mathrm{Fr}=\frac{\sqrt{\mathrm{u}^{2}+\mathrm{v}^{2}}}{\mathrm{c}}
$$


The right hand side of the system contains the sources and sinks of momentum arising from the bed slopes and the friction losses along the two coordinate directions,

$$
\mathbf{G}=\left(\begin{array}{c}
-\mathrm{i} \\
\operatorname{gh}\left(\mathrm{S}_{0 \mathrm{x}}-\mathrm{S}_{\mathrm{fx}}\right)+\mathrm{D}_{\mathrm{ix}} \\
\operatorname{gh}\left(\mathrm{S}_{0 \mathrm{y}}-\mathrm{S}_{\mathrm{fy}}\right)+\mathrm{D}_{\mathrm{iy}}
\end{array}\right)
$$

The bed slopes are the spatial partial derivatives of the bottom elevation $z$,

$$
\mathrm{S}_{0 \mathrm{x}}=-\frac{\partial \mathrm{z}}{\partial \mathrm{x}}, \quad \mathrm{S}_{0 \mathrm{y}}=-\frac{\partial \mathrm{z}}{\partial \mathrm{y}}
$$

and the friction slopes are defined in terms of the Manning roughness coefficient $n$,

$$
S_{f x}=\frac{n^{2} u \sqrt{u^{2}+v^{2}}}{h^{\frac{4}{3}}}, \quad S_{f y}=\frac{n^{2} v \sqrt{u^{2}+v^{2}}}{h^{\frac{4}{3}}}
$$

The infiltration rate is defined like in the one-dimensional approach and the momentum transfers are estimated as :

$$
\mathrm{D}_{\mathrm{ix}}=\frac{\mathrm{ui}}{2}, \quad \mathrm{D}_{\mathrm{iy}}=\frac{\mathrm{vi}}{2}
$$

\section{Polar Model}

Pure radial flow typifies the problems of expansions or contractions in a continuous representation. So, it presents some interest for the simulation of surface irrigation from a corner.

In transforming Eq. (11) from the cartesian $(x, y, t)$ to the polar frame $(r, \phi, t)$, the variables $(h, u, v)$ become the set $\left(h, u_{r}, u_{\phi}\right)$. The transformation is simplified by assuming pure radial flow, that is, independent of the angular variable $\phi,\left(u_{\phi}=0, \partial h / \partial \phi=0, \partial u_{r} / \partial \phi=0\right)$. Considering that :

$$
\mathrm{r}=\sqrt{\mathrm{x}^{2}+\mathrm{y}^{2}}, \quad \phi=\tan ^{-1}(\mathrm{y} / \mathrm{x})
$$

and using the directional derivatives 


$$
\begin{gathered}
\frac{\partial r}{\partial x}=\cos \phi, \quad \frac{\partial r}{\partial y}=\sin \phi \\
\frac{\partial \phi}{\partial x}=\frac{-\sin \phi}{r}, \quad \frac{\partial \phi}{\partial y}=\frac{\cos \phi}{r}
\end{gathered}
$$

the mass or continuity equation becomes

$$
\frac{\partial \mathrm{h}}{\partial \mathrm{t}}+\frac{1}{\mathrm{r}} \frac{\partial \mathrm{hru}_{\mathrm{r}}}{\partial \mathrm{r}}=-\mathrm{i}
$$

and the two momentum equations combine to give a single radial momentum equation

$$
\frac{\partial h u_{r}}{\partial t}+\frac{1}{r} \frac{\partial h_{r u}^{2}}{\partial r}+g \frac{\partial h^{2} / 2}{\partial r}=g h \frac{\partial z}{\partial r}+g \frac{n^{2} u_{r}\left|u_{r}\right|}{h^{1 / 3}}+\frac{u_{r} i}{2}
$$

It is possible to rewrite the system of Eqs. (20) and (21) into conservative form :

$$
\begin{gathered}
\frac{\partial \mathrm{h}}{\partial \mathrm{t}}+\frac{\partial \mathrm{hu} \mathrm{r}_{\mathrm{r}}}{\partial \mathrm{r}}=-\frac{h \mathrm{u}_{\mathrm{r}}}{\mathrm{r}}-\mathrm{i} \\
\frac{\partial \mathrm{hu}}{\partial \mathrm{r}}+\frac{\partial\left(\mathrm{hu}_{\mathrm{r}}^{2}+\mathrm{gh}^{2} / 2\right)}{\partial \mathrm{r}}=-\frac{\mathrm{hu}_{\mathrm{r}}^{2}}{\mathrm{r}}+\mathrm{gh} \frac{\partial \mathrm{z}}{\partial \mathrm{r}}+\mathrm{g} \frac{\mathrm{n}^{2} \mathrm{u}_{\mathrm{r}}\left|\mathrm{u}_{\mathrm{r}}\right|}{\mathrm{h}^{1 / 3}}+\frac{\mathrm{u}_{\mathrm{r}} \mathrm{i}}{2}
\end{gathered}
$$

or

$$
\begin{gathered}
\frac{\partial \mathrm{h}}{\partial \mathrm{t}}+\frac{\partial \mathrm{q}}{\partial \mathrm{r}}=-\frac{\mathrm{q}}{\mathrm{r}}-\mathrm{i} \\
\frac{\partial \mathrm{q}}{\partial \mathrm{t}}+\frac{2 \mathrm{q}}{\mathrm{h}} \frac{\partial \mathrm{q}}{\partial \mathrm{r}}+\left(\mathrm{gh}-\frac{\mathrm{q}^{2}}{\mathrm{~h}^{2}}\right) \frac{\partial \mathrm{h}}{\partial \mathrm{r}}=-\frac{\mathrm{q}^{2}}{\mathrm{hr}}+\mathrm{gh}\left(\mathrm{S}_{0}-\mathrm{S}_{\mathrm{fr}}\right)+\frac{\mathrm{qi}}{2 \mathrm{~h}}
\end{gathered}
$$

with $q=h u_{r}$ and

$$
\mathrm{S}_{\mathrm{fr}}=\frac{\mathrm{n}^{2} \mathrm{q}|\mathrm{q}|}{\mathrm{h}^{10 / 3}}
$$

This form of the equations presents the advantage of being similar to Eqs. (1) and (2) in the partial derivative terms, that is, it is a system with the same Jacobian matrix and, hence, the same 
mathematical properties. Therefore, ignoring the treatment of the right hand side of the equations, the one-dimensional numerical techniques can be adapted directly. These techniques as well as the treatment of the source terms are discussed in next section.

\section{NUMERICAL SCHEME}

The numerical scheme used for discretizing Eqs. (1) and (2), and Eqs. (22) and (23) is the explicit McCormack's predictor-corrector (McCormack 1971). This technique is second order accurate in space and time, is conceptually simple and has been successfully used to simulate unsteady free surface flow (Fennema and Chaudhry 1986, Bellos et al. 1991, García-Navarro and Savirón 1992, García-Navarro and Alcrudo 1992). For a general conservation system

$$
\frac{\partial \mathbf{U}}{\partial \mathrm{t}}+\frac{\partial \mathbf{F}}{\partial \mathrm{x}}=\mathbf{G}
$$

the procedure advances the solution from time level $n$ to time level $n+1\left(t^{n+1}=t^{n}+\Delta t\right)$ at the interior points $2 \ldots N-1$ in a uniform discrete mesh $\left\{x_{i}, i=1, N\right\}$ in two steps. The predicted $(p)$ values are obtained from:

$$
\mathbf{U}_{\mathrm{i}}^{\mathrm{p}}=\mathbf{U}_{\mathrm{i}}^{\mathrm{n}}-\frac{\Delta \mathrm{t}}{\Delta \mathrm{x}}\left(\mathbf{F}_{\mathrm{i}+1}^{\mathrm{n}}-\mathbf{F}_{\mathrm{i}}^{\mathrm{n}}\right)+\Delta \mathrm{t} \mathbf{G}_{\mathrm{i}}^{\mathrm{n}}
$$

In the final updating, the following is used:

$$
\mathbf{U}_{\mathrm{i}}^{\mathrm{n}+1}=\frac{1}{2}\left(\mathbf{U}_{\mathrm{i}}^{\mathrm{n}}+\mathbf{U}_{\mathrm{i}}^{\mathrm{p}}-\frac{\Delta \mathrm{t}}{2 \Delta \mathrm{x}}\left(\mathbf{F}_{\mathrm{i}}^{\mathrm{p}}-\mathbf{F}_{\mathrm{i}-1}^{\mathrm{p}}\right)+\frac{\Delta \mathrm{t}}{2} \mathbf{G}_{\mathrm{i}}^{\mathrm{p}}\right)
$$

In Glaister (1991) the pure radial flow equations (Eqs. 22 and 23) in the homogeneous case (no bed slope, no friction, no infiltration) are discretized using the explicit Roe scheme (Roe 1981). The source terms are upwinded applying a decomposition on the basis of eigenvectors of the approximate Jacobian. This step has been avoided in the work presented here. Instead, a pointwise semi-implicit 
discretization has proved efficient in reducing instabilities at the advancing front. For the friction term, in the prismatic problem for instance,

$$
\begin{gathered}
\mathrm{S}_{\mathrm{f}}=\frac{\mathrm{Q}|\mathrm{Q}|}{\mathrm{K}^{2}}, \quad \mathrm{~K}=\frac{\mathrm{AR}^{2 / 3}}{\mathrm{n}} \\
\mathrm{S}_{\mathrm{fi}} \approx\left(\frac{|\mathrm{Q}|}{\mathrm{K}^{2}}\right)_{\mathrm{i}}^{\mathrm{n}}\left(\theta \mathrm{Q}_{\mathrm{i}}^{\mathrm{n}}+(1-\theta) \mathrm{Q}_{\mathrm{i}}^{\mathrm{n}+1}\right), \quad 0 \leq \theta \leq 1
\end{gathered}
$$

And for the geometrical source term in the radial problem

$$
\left(\frac{\mathrm{u}_{\mathrm{r}}^{2} \mathrm{~h}}{\mathrm{r}}\right)_{\mathrm{i}}=\left(\frac{\mathrm{q}^{2}}{\mathrm{rh}}\right)_{\mathrm{i}} \approx\left(\frac{\mathrm{q}}{\mathrm{rh}}\right)_{\mathrm{i}}^{\mathrm{n}}\left(\theta \mathrm{q}_{\mathrm{i}}^{\mathrm{n}}+(1-\theta) \mathrm{q}_{\mathrm{i}}^{\mathrm{n}+1}\right)
$$

\section{Boundary conditions}

Having used an explicit scheme for the interior points, the method of characteristics has to be applied to specify conditions at the boundaries. A detailed description of the principles of this method may be found in several references (see Cunge et al. 1980). The flow regime at the upstream and downstream ends determines the number of required boundary conditions. The application to a prismatic one-dimensional channel is well described in García-Navarro and Savirón (1992). The implementation for the pure radial flow equations is outlined next. From Eqs. (24) and (25) it is possible to write

$$
\frac{\mathrm{Dq}}{\mathrm{Dt}}+\left(-\frac{\mathrm{q}}{\mathrm{h}} \pm \sqrt{\mathrm{gh}}\right) \frac{\mathrm{Dh}}{\mathrm{Dt}}=\mp \frac{\mathrm{q}}{\mathrm{r}} \sqrt{\mathrm{gh}}+\mathrm{i}\left(-\frac{3 \mathrm{q}}{2 \mathrm{~h}} \pm \sqrt{\mathrm{gh}}\right)+\mathrm{gh}\left(\mathrm{S}_{0}-\mathrm{S}_{\mathrm{fr}}\right)
$$

that hold along the trajectories or characteristic lines

$$
\frac{\mathrm{dr}}{\mathrm{dt}}=\frac{\mathrm{q}}{\mathrm{h}} \pm \sqrt{\mathrm{gh}}
$$

respectively. The first identity in Eq. (33), holds along the forward characteristic, and is used at the downstream boundary; the second identity holds along the backward characteristic, and is used at the upstream boundary. Since a fixed grid is involved, spatial interpolation over the nodal points bracketing the foot of the characteristics at time level $n$ is necessary. The information carried by the characteristics to 
the points at the boundaries is complemented by the boundary conditions. The solution is obtained through an iterative procedure similar to the one detailed in García-Navarro and Savirón (1992). In the work presented here, the imposed boundary conditions consisted of a hydrograph $q=q(t)$ upstream and a zero spatial derivative of $h$ downstream (once the advance phase has been completed).

\section{Numerical experiment 1}

A numerical experiment was performed to assess the reliability of the one-dimensional Cartesian and Polar models. In this experiment, results are compared to those of the two-dimensional Cartesian model presented by Playán et al. (1994). In the latter, Eq. (11) is solved by means of an explicit leapfrog numerical scheme. Their two-dimensional model simulated both parallel and radial flow.

The experiment simulates an irrigation on a square 1 ha $(100 \mathrm{~m} \times 100 \mathrm{~m})$ level-basin receiving a constant discharge of $0.1 \mathrm{~m}^{3} \mathrm{~s}^{-1}$. Infiltration is characterized by the following parameters : $k=0.006 \mathrm{~m}$ $\min ^{-a}, a=0.5$, and $f_{0}=0$. Surface roughness is characterized by a Manning roughness factor $n=0.14$. If the inflow discharge is distributed evenly along one of its $100 \mathrm{~m}$ sides, the flow will be parallel, with an inflow of $0.001 \mathrm{~m}^{3} \mathrm{~s}^{-1}$. If a point inflow is located at one of the $\pi / 2 \mathrm{rad}$ corners, the flow will be radial until the moment when the advancing front reaches one of the corners. Unless otherwise stated, the distance separating the inflow point and the upstream node of the Polar model $\left(r_{0}\right)$ is $5 \mathrm{~m}$, and the angle of radial inflow $(\alpha)$ is $\frac{\pi}{2}$. In this case, the inflow radial unit discharge $\left(q_{0}\right)$ can be computed as:

$$
\mathrm{q}_{0}=\frac{\mathrm{Q}_{\mathrm{T}}}{\mathrm{r}_{0} \alpha}=\frac{0.1}{5 \frac{\pi}{2}} \mathrm{~m}^{2} \mathrm{~s}^{-1} \mathrm{rad}^{-1}
$$

A node spacing of $1 \mathrm{~m}$ was used in the one-dimensional Cartesian and Polar models. For the twodimensional Cartesian model, the node spacing was set to $5 \mathrm{~m}$. Therefore, 101 and 441 nodes were used for one-dimensional and two-dimensional simulation, respectively. Some experimental results are displayed in Figs. 1 to 4. 
Fig. 1 shows the free surface and infiltrated water profiles during the propagation of the irrigation front $(t=40 \mathrm{~min})$. The horizontal axis represents the radius in the radial flow case and the longitudinal distance in the parallel flow case. Note the agreement between the Polar model and the two-dimensional Cartesian model reproducing radial flow. The surface profiles obtained with the twodimensional Cartesian model are of poorer quality than those from the Polar model. This is particularly true in the vicinity of the advancing front. This can be explained by the lower spatial resolution obtained in the two-dimensional cartesian model and by the higher order accuracy of the McCormack numerical scheme. In the radial flow case, the two-dimensional Cartesian model provides values of the dependent variables at the location of the inflow point, whereas the Polar model starts at $r_{0}$. This peculiarity also introduces a small conceptual difference between the results of the two models : at time $t=0$ the Polar model considers the area between $r=0$ and $r=r_{0}$ flooded. At a given time, the advance radius of the radial flow is much larger than the advance distance of the parallel flow. Similarly, the point source results in an important buildup of surface water in all the flooded domain, as compared to the parallel flow case.

Fig. 2 presents the corresponding advance curves. The models used to describe each type of flow can be said to agree satisfactorily. Taking into account the different geometrical meanings of the two abscissae, the advance curve is more concave for radial flow than it is for parallel flow. When the advance curves are expressed in terms of area instead of distance to the inlet, the differences between the two types of flow are reduced. At time $40 \mathrm{~min}$, radial flow had covered 16\% less area than parallel flow.

Fig. 3 depicts the time evolution of the mass balance error. Observe that the one-dimensional Cartesian and Polar models tend to a bounded error which is small in both cases and comparable to that of the two-dimensional Cartesian model. The error is closely related to the grid size ( $1 \mathrm{~m}$ in this case) and sensitive to the position of the upstream node in the Polar model $\left(r_{0}\right)$. This is illustrated in Fig. 4, 
where the final error and upstream depth (at time $40 \mathrm{~min}$ ) are presented for values of $r_{0}$ ranging from 0.5 to $10 \mathrm{~m}$. For small values of $r_{0}$ the mass balance error becomes unacceptable due to the presence of a singularity at $r=0$. Observe also in Fig. 4 that the upstream depth increases with decreasing $r_{0}$, up to a point in which numerical stability is attained. Values of $r_{0}$ under $0.5 \mathrm{~m}$ resulted in aborted runs. This problem was overcome by selecting a finer computational mesh. In view of these results, a $1 \mathrm{~m}$ mesh and $r_{0}=5 \mathrm{~m}$ were used in all subsequent model executions.

The Polar model developed here could be used in irrigation system design applications. As shown in Fig. 1, the model can produce high quality surface and infiltrated flow profiles using less nodes than a two-dimensional Cartesian model. In the particular case of simulating a corner irrigated basin, computational time could be effectively saved by using the radial flow model at a first stage of the simulation. The problem can therefore be reduced by one spatial dimension until the advancing front reaches one of the basin corners. At this point the second stage would be initiated with interpolation of the values of the dependent variables at the nodes of a two-dimensional net. The computations would be continued with a two-dimensional Cartesian model.

\section{APPLICATION: THE INVERSE PROBLEM}

In the following section, the one-dimensional Cartesian and Polar models will be used to build predictive inverse problem solvers. The proposed Polar model can be used to simulate level-basin irrigation as long as the flow remains radial. Radial flow conditions will prevail before the flow reaches a field boundary that does not contain the inflow point. Ideally, this procedure could be applied to irrigation events with the water source inflow at any location along the boundary $(0<\alpha \leq 2 \pi)$.

\section{Objective Functions}


The objective function is an expression of the difference between observed and model estimated values of a variable at different locations and/or times as a function of the unknown model parameters. Katopodes (1990) pointed out the advantages of using water-depth measurements over advance times to define the objective function.

The Cartesian objective function is similar to the one used by Katopodes et al. (1990). In the present work, two formulations will be used depending on the parameters to be estimated. Estimation was limited to two parameters at a time, these being $n$ and $k$ or $k$ and $a$. The objective function $(O)$ will be formulated as :

$$
\begin{aligned}
& O(n, k)=\sum_{j=1}^{J}\left[h_{j}^{\prime}\left(x_{j}, t_{j}\right)-h\left(x_{j}, t_{j}, n, k\right)\right]^{2} \\
& O(k, a)=\sum_{j=1}^{J}\left[h_{j}^{\prime}\left(x_{j}, t_{j}\right)-h\left(x_{j}, t_{j}, k, a\right)\right]^{2}
\end{aligned}
$$

where $h^{\prime}$ is the field measured flow depth and $J$ is the total number of field observations. Both $h$ and $h^{\prime}$ are expressed in millimeters in all objective functions.

The Polar objective function is similar to Eqs. (36) and (37), but needs to be constructed in terms of $r$ instead of $x$. In cartesian space, all evenly spaced measurements represent the same field area. In polar space, the area represented by an observation located at a certain radius $r_{j}$ can be considered proportional to $r_{j}^{2}$. Therefore, two additional functions are proposed for testing: the hereforth called Weighted Polar objective functions.

$$
\begin{aligned}
& O(n, k)=\sum_{j=1}^{J} \pi r_{j}^{2}\left[h_{j}^{\prime}\left(r_{j}, t_{j}\right)-h\left(r_{j}, t_{j}, n, k\right)\right]^{2} \\
& O(k, a)=\sum_{j=1}^{J} \pi r_{j}^{2}\left[h_{j}^{\prime}\left(r_{j}, t_{j}\right)-h\left(r_{j}, t_{j}, k, a\right)\right]^{2}
\end{aligned}
$$




\section{Minimization Techniques}

Different methods exist for estimating the nonlinear parameters of Eqs. 36-39. Any multidimensional minimization technique is based on the iterative selection of search directions. Within each iteration, a line minimization is performed to find the step length that takes $O$ to a minimum value. Some methods use the gradient of the objective function to guide the minimization process (Katopodes et al. 1990), while others do not use the derivatives of the objective function (Walker and Busman 1990, Azevedo 1992). The computation converges when in two successive iterations both estimated parameters are modified by an amount less than or equal to an arbitrary tolerance value $(0.05 \%$ was used in this work). If the final value of both parameters differs from the solution by less than the tolerance, the computation is said to converge to the solution.

Press et al. (1988) presented a comprehensive discussion on minimization techniques and their implementation. Using their source code, a gradient and a non-gradient minimization methods were implemented and applied to estimate level-basin irrigation parameters.

The gradient Polak-Ribiere approach was successfully used by Katopodes et al. (1990). These authors estimated the gradient of $O$ from a 1\% forward perturbation, therefore requiring three function evaluations to estimate the value and the gradient of $O$ in a two-dimensional search. This approach was implemented in the present study and will be referred to as Polak 1 . Consideration was given to the fact that in the vicinity of a valley bottom, a forward (of backward) finite difference approximation provides a poor estimation of the gradient across the valley, as compared to a centered difference. This is the reason why a variant of the same gradient method, Polak 2, was implemented. The drawback of this approach is that five function evaluations are required to estimate the value and the gradient of $O$ in a two-dimensional search. The advantage of Polak 2 may reside in a reduced number of iterations, due to better search directions. 
Similarly, the Powell search method is based on the conjugate gradient concept, but it does not make use of the gradient information. The version implemented in this research discards the direction of largest decrease in order to avoid linear dependence between successive search directions. The same method was successfully applied by Azevedo (1992) to the estimation of two and three infiltration parameters based on the observation of advance in irrigated furrows.

\section{Numerical experiment 2}

A numerical experiment was devised to study the performance of the inverse method based on the Polar model. In this experiment, minimizations are presented for radial and polar flow, nonweighted and weighted objective functions, $n-k$ and $k-a$ estimation, and Polak (1 and 2) and Powell searches. Due to the exploratory nature of this research, model results were used as field data (Katopodes et al. 1990). Therefore, sensu estricto, the discussion can only be extended to the capability of the minimization techniques to identify the value of the parameters that yield the same results as the hydraulic simulation models.

The numerical experiment considers again a square 1 ha level basin receiving a $0.1 \mathrm{~m}^{3} \mathrm{~s}^{-1}$ inflow. The purpose of this experiment was to establish an objective comparison between radial and parallel flow. A common protocol was used for data collection in both types of flow. Flow depth values were obtained at $5 \mathrm{~m}$ intervals starting at $5 \mathrm{~m}$ from the inlet, to a distance of $50 \mathrm{~m}$, and at $5 \mathrm{~min}$ intervals to a final time of $30 \mathrm{~min}$, for a total of 60 measurements. Observations were selected on a straight line along the flow direction in both the parallel and radial flow cases. If the radial flow experiment was to be performed in the field, the upstream $5 \mathrm{~m}$ in radius quarter of a circle should be impermeabilized to prevent infiltration. This would make the actual and the modeled phenomena more similar to each other. 
Node spacing for the numerical solution of the flow equations was set to $1 \mathrm{~m}$. In the Polar model, the upstream node is again located $5 \mathrm{~m}$ downstream from the inlet. The parameter $f_{0}$ was set to 0 in all cases. A $100 \mathrm{MHz}$ Pentium ${ }^{\circledR}$ personal computer was used to perform the calculations. Each objective function evaluation took $40 \mathrm{~s}$ and $53 \mathrm{~s}$ of computational time for the one-dimensional Cartesian and Polar models, respectively. In order to assess the uniqueness of the solution, four different initial points were considered for each minimization run. Table 1 contains the location of the solution and the four corresponding initial points for the $n-k$ and $k-a$ minimizations. Figure 5 presents the valleys of minima for each combination of parameter sets and objective functions. Each valley was plotted from 121 function evaluations computed at equidistant points along the $n-k$ or $k-a$ axes. In all cases, the solution point is located at the center of the plotted region. The value of the objective function is 0 at this point since the simulated and the 'real' flow depth measurements match exactly. Inspection of the six plots reveals that the $n-k$ valleys are better suited for minimization than the $k-a$ valleys. The appearance of a long, narrow valley bottom for $k$ - $a$ pairs indicates that different sets of pairs of $k$ and $a$ values result in similar flow depth measurement sets. Thus, the search for $k$ and $a$ will be hindered by the substitutive effect between the two parameters. The $n-k$ valleys do not seem to change much with changes in the objective function. The bottom of $k$ - $a$ valleys, however, shortens and widens when either of the Polar objective functions is used.

Table 2 presents the results of $n-k$ estimation from starting points $a, b, c$, and $d$. The table indicates the number of iterations and objective function evaluations per iteration required for convergence. Results are provided only for cases where the algorithm converged to the solution. Lack of convergence to the solution was due to non-uniqueness of the solution. On the basis of objective function evaluations, polar performed best among objective functions, followed by Cartesian and Weighted Polar. Two minimization methods, Polak 2 and Powell, converged to the solution in all cases. Of the two methods, Polak 2 used significantly fewer function evaluations. The Powell method uses fewer iterations than Polak, but requires more function evaluations per iteration. Polak 1 uses fewer 
function evaluations than Polak 2, but fails to converge to the solution more often. Radial flow seems therefore to be well suited for the estimation of $n$ and $k$ in level basin irrigation events. The best choice for minimization technique was the Polak-Ribiere method with a centered finite difference estimation of the gradient. The Weighted Polar objective function was less efficient for parameter estimation than the Polar function. Figure 5 (left) presents the convergence path for points c, b and c in the Cartesian, Polar and Weighted Polar functions, using the Polak 2 method. Figure 6 presents a detail plot of the convergence path from initial point $b$ for the Polar function and the Polak 2 and Powell methods.

Table 3 presents the results of $k$ - $a$ estimation from starting points $\mathrm{e}, \mathrm{f}, \mathrm{g}$, and $\mathrm{h}$. The most noticeable difference with respect to the results of Table 2 is that, for the studied cases, convergence to the solution was infrequent. This confirms the previously made observations regarding the characteristics of the solution region for $k$ - $a$ estimation (Fig. 5). Convergence to the solution was achieved more frequently when using the Polar objective function, while the Weighted Polar objective function ranked second. Note that none of the objective functions performs satisfactorily. Among minimization methods, the Powell method was the only one that converged to the solution at a significant rate. The combination of Polar and Powell yielded the solution in all cases. Even in this case, convergence to the solution was obtained at the expense of $156 \%$ increase in computational time, compared to $n-k$ estimation. This increment was mostly due to the increased number of required Powell iterations, from 2.8 to 6.0 for the Polar function. Convergence paths for points e, $\mathrm{g}$ and $\mathrm{f}$ in the Cartesian, Polar and Weighted Polar functions, using the Powell method, are shown in Fig. 5. A detailed plot of the convergence paths from initial point $\mathrm{g}$ for the Polar function and the Polak 2 and Powell methods is presented in Fig. 7. The difference in computational effort associated with $n-k v s . k-a$ estimation can be appreciated from Figs. 6 and 7, which show the total number of evaluations required for each case.

\section{SUMMARY AND CONCLUSIONS}


Two hydraulic simulation models suited for one-dimensional parallel and radial flow have been presented. In both cases, the shallow water equations are solved using an explicit finite-difference McCormack scheme. Both models have been applied to the simulation of level-basin irrigation introducing appropriate friction and infiltration terms. The shallow water equations for radial flow were cast in cylindrical polar coordinates. Pointwise semi-implicit discretization of the friction and geometrical source terms was used to reduce numerical instabilities at the advancing front. At the inlet point $(r=0)$ the governing equations are singular. In the region near the inlet, a detailed description of the profile can be obtained solving the steady state equations of the radial flow. If the time-dependent equations (Eqs. 24 and 25) are solved, the flow profile near the inlet is well reproduced if a fine mesh is used. On coarse grids the solution is distorted, therefore making it advisable to locate the first node away from $r=0$. A distance of $5 \mathrm{~m}$ proved to be satisfactory in the studied cases. Results from the Polar model were successfully compared to those from an existing two-dimensional Cartesian model simulating radial flow.

The hydraulic models were coupled to minimization routines to build predictive level-basin inverse problem solvers. When using simulated data as input, results indicate that pairs of roughness and infiltration parameters can be identified not only under parallel but also under radial flow conditions from depth measurements. When determining $n$ and $k$ using the Polak 2 minimization method, a solution was obtained using more iterations with the Cartesian objective function than with the Polar objective function (101 vs. 93). The total computational time was smaller for the Cartesian function than for the Polar function $(67 \mathrm{~min} v s .82 \mathrm{~min}$ ). When determining $k$ and $a$, the Polar objective function seems better suited for solving the inverse problem than the Cartesian objective function, although the average Polar run took over four hours of computational time. Searching for $k$ and $a$, only the Powell method systematically succeeded in converging to the solution. 
In this research uniformity of infiltration, roughness and soil surface elevation has been assumed. Deviations from this hypothesis make this problem more difficult to solve. If any of the considered parameters $\left(k, a, f_{0}, n\right.$ or $\left.z\right)$ is spatially varied, a two dimensional model such as the one used in this research for comparison purposes is required. The same applies to field geometries not satisfactorily explained by one-dimensional Cartesian or Polar models. Coupling of a two-dimensional model to a minimization routine should only have the disadvantage of the resulting increase in computational time.

It is concluded from this work that estimation of the infiltration and roughness parameters is as least as possible for radial flow as it is for parallel flow. Estimation of surface irrigation parameters resulted more difficult when the infiltration exponent $a$ was among the estimated parameters. This can be attributed to the fact that $a$ is nonlinear, while $n$ and $k$ are linear. The performance of the Weighted Polar objective function was poor. This weighing scheme puts little weight on upstream depths, which at long times tend to reach steady state. Upstream depth measurements are, therefore, more reliable than downstream measurements and should have a large influence on the solution.

In future work, different options could be envisaged in order to speed up the numerical models. The allowed time step used in explicit schemes is limited by the Courant-Friedrichs-Lewy stability condition. Moving to an implicit approach could help to relax this constraint. On the other hand, a grid with an increasingly variable number of nodes could be adapted to the explicit scheme. This could be an advantage as it would avoid computation at the unflooded nodes. Convergence to the solution could be improved with alternative minimization methods and/or weighing schemes. Katopodes et al (1990), combined two different methods in their inverse problem solver, and used them alternatively when convergence to the solution was not achieved in a short number of iterations. This type of approach will be particularly important for field applications, when the solution is not previously known and uniqueness of the solution is a crucial issue. 


\section{APPENDIX I : REFERENCES}

Abbott, M. B. (1992) Computational hydraulics. 3rd Edition. Ashgate, UK, 326 pp.

Azevedo, C. A. V. (1992). "Real-time solution of the inverse furrow advance problem." Ph. D. thesis, Utah State University, Logan, Utah. 263 pp.

Bautista, E. and Wallender, W. W. (1993). "Identification of furrow intake parameters from advance times and rates." J. Irrig. Drain. Engrg., ASCE , 119(2), 295-311.

Bellos, C. V., Soulis, J. V. and Sakkas, J. G. (1991). "Computation of two-dimensional dam-break induced flows." Adv. Water Resources, 14, 31-41.

Clemmens, A. J. (1991). "Direct solution to surface irrigation advance inverse problem." J. Irrig. Drain. Engrg., ASCE, 117(4), 578-594.

Clemmens, A. J. and Keats, J. B. (1992a). "Bayesian inference for feedback control. I. Theory." J. Irrig. Drain. Engrg., ASCE, 118(3), 397-415.

Clemmens, A. J. and Keats, J. B. (1992b). "Bayesian inference for feedback control. II: Surface irrigation example." J. Irrig. Drain. Engrg., ASCE, 118(3), 416-432.

Cunge, J. A., Holly, F. M. and Verwey, A. (1980). Practical aspects of computational river hydraulics. Pitman Pub. Inc., Bath, UK. 420 pp. 
Fennema, R. J. and Chaudhry, M. H. (1986). “Explicit numerical schemes for unsteady free-surface flows with shocks". Water Resour. Res., 22(13), 1923-1930.

García-Navarro, P. and Alcrudo, F. (1992) . “1D open channel flow simulation using TVD McCormack scheme". J. of Hydr. Engrg, ASCE, 118(10), 1359-1372.

García-Navarro, P., and Savirón, J.M. (1992). "McCormack's method for the numerical simulation of onedimensional discontinuous unsteady open channel flow." J. of Hydraulic Research, 308(1), 95-105.

Glaister, P. (1991). "Shallow water flow with cylindrical symmetry." Journal of Hydraulic Research, 298(2), 219-227.

Hanson, B. R., Prichard, T. L. and Schulbach, H. (1993). "Estimating furrow infiltration." Agricultural Water Management, 24, 281-298.

Katopodes, N. D. (1990). "Observability of surface irrigation advance." J. Irrig. Drain. Engrg., ASCE, 116(5), 656-675.

Katopodes, N. D., Tang, J. and Clemmens, A. J. (1990). "Estimation of surface irrigation parameters." J. Irrig. Drain. Engrg., ASCE, 116(5), 676-696.

McCormack, R. W. (1971). "Numerical solution of the interaction of a shock wave with a laminar boundary layer." Lecture Notes in Physics. Springer-Verlag, Berlin, Germany. 8, 151-163.

Playán, E., Walker, W. R. and Merkley G. P. (1994). "Two-dimensional simulation of basin irrigation. I : Theory." J. Irrig. and Drain. Engrg., ASCE, 120(5), 837-856. 
Press, W. H., Flannery, B. P., Teukolsky, S. A. and Vetterling, W. T. (1988). Numerical recipes in C. Cambridge University Press, Cambridge. 735 pp.

Roe, P. L. (1981). “Approximate Riemann solvers, parameter vectors and difference schemes.” J. Comput. Physics, 43, 357-372.

Scaloppi, E., Merkley, G. P. and Willardson, L. S. (1995). "Intake parameters from advance and wetting phases of surface irrigation." J. Irrig. and Drain. Engrg., ASCE, 121(1), 57-70.

Valiantzas, J. D. (1994). "Simple method for identification of border infiltration and roughness characteristics." J. Irrig. and Drain. Engrg., ASCE, 120(2), 233-249.

Walker, W. R. and Busman, J. D. (1990). "Real-time estimation of furrow infiltration." J. Irrig. Drain. Engrg., ASCE. 116(3), 299-318. 


\section{APPENDIX II : NOTATION}

The following symbols are used in this paper:

A Cross-sectional area of flow $\left(\mathrm{L}^{2}\right)$;

a Exponent of the Kostiakov-Lewis infiltration equation ;

b Channel width (L) ;

c $\quad$ Speed of surface perturbations $\left(\mathrm{LT}^{-1}\right)$;

$\mathrm{D}_{\mathrm{i}} \quad$ Term for momentum transfer associated to infiltration $\left(\mathrm{L}^{2} \mathrm{~T}^{-2}\right)$;

E Vector of conserved dependent variables ;

F Vector of fluxes of the conserved variables ;

Fr Dimensionless Froude number ;

$\mathrm{f}_{0} \quad$ Parameter of the Kostiakov-Lewis infiltration equation (LT-1) ;

G Sources and sinks vector ;

g Acceleration due to gravity $\left(\mathrm{LT}^{-2}\right)$;

h $\quad$ Flow depth $(\mathrm{L})$;

h' $\quad$ Field measured flow depth $(\mathrm{L})$;

$\mathrm{I}_{1} \quad$ Unit hydrostatic pressure force term $\left(\mathrm{L}^{2}\right)$;

$\mathrm{I}_{2} \quad$ Unit force term associated to longitudinal width variations (L) ;

i Infiltration rate $\left(\mathrm{LT}^{-1}\right)$

J Total number of field observations ;

K Conveyance ( L $\left.^{2} \mathrm{~T}^{-1}\right)$

k Parameter of the Kostiakov-Lewis infiltration equation (T-a) ;

N Number of nodes ;

n Manning roughness coefficient ;

Q Unit discharge $\left(\mathrm{L}^{2} \mathrm{~T}^{-1}\right)$;

Q $\quad$ Total inflow discharge $\left(\mathrm{L}^{3} \mathrm{~T}^{-1}\right)$; 
q Radial unit discharge $\left(\mathrm{L}^{2} \mathrm{~T}^{-1} \mathrm{rad}^{-1}\right)$;

$\mathrm{q}_{0} \quad$ Upstream radial unit discharge $\left(\mathrm{L}^{2} \mathrm{~T}^{-1} \mathrm{rad}^{-1}\right)$;

r Radial spatial coordinate (L) ;

$\mathrm{r}_{0} \quad$ Radial spatial coordinate at the upstream node (L) ;

So Channel slope ;

$\mathrm{S}_{\mathrm{f}} \quad$ Friction slope ;

t $\quad$ Time $(\mathrm{T})$;

U Vector of dependent variables ;

$\mathrm{u}_{\phi} \quad$ Flow velocity in the $\phi$ direction $\left(\mathrm{LT}^{-1}\right)$;

$\mathrm{u}_{\mathrm{r}} \quad$ Flow velocity in the $\mathrm{r}$ direction $\left(\mathrm{LT}^{-1}\right)$;

u Flow velocity (LT-1);

$\mathrm{v} \quad$ Flow velocity in the $\mathrm{y}$ direction $\left(\mathrm{LT}^{-1}\right)$;

x Cartesian spatial coordinate (L) ;

y Cartesian spatial coordinate (L) ;

z Bed elevation (L) ;

$\alpha \quad$ Angle of radial inflow ;

$\phi \quad$ Polar spatial coordinate ;

$\eta \quad$ Integration variable for flow depth (L) ;

$\theta \quad$ Weighing parameter for source term discretization ; and

$\tau \quad$ Opportunity time (T) ; 
APPENDIX III : TABLES

Table 1. Coordinates of the starting points and solutions for numerical experiment 2.

Table 2. Results of the numerical experiment 2: optimization for $n$ and $k$ for different objective functions and optimization methods. The sign ' - ' indicates failure to converge to the solution.

Table 3. Results of the numerical experiment 2 : optimization for $k$ and $a$ for different objective functions and optimization methods. The sign ' - ' indicates failure to converge to the solution. 


\section{APPENDIX IV : FIGURES}

Fig. 1. Numerical experiment 1 : surface and infiltrated water profiles at $t=40 \mathrm{~min}$ for the parallel and radial flow cases simulated with the Polar, one-dimensional Cartesian and two-dimensional Cartesian models.

Fig. 2. Numerical experiment 1 : advance trajectories for the parallel and radial flow cases simulated with the Polar, one-dimensional Cartesian and two-dimensional Cartesian models.

Fig. 3. Numerical experiment 1 : time evolution of mass balance error for the parallel and radial flow cases simulated with the Polar, one-dimensional Cartesian and two-dimensional Cartesian models.

Fig. 4. Numerical experiment 1 : Dependence of the final $(t=40 \mathrm{~min})$ mass balance error and upstream depth on the distance from the inlet to the upstream node for the Polar model.

Fig. 5. Numerical experiment 2: Valleys of minima and selected convergence paths for different optimization cases : $n-k$ (left) and $k-a$ (right) searches; Cartesian (top) Polar (center) and Weighted Polar (bottom) objective functions. The solution point is always located at the center of each plot. Polak 2 and Powell optimization methods are presented for $n-k$ and $a-k$ search, respectively.

Fig. 6. Numerical experiment 2: Convergence path for $n-k$ search from initial point $b$ using a Polar objective function in conjunction with Polak 2 and Powell optimization methods. 
Fig. 7. Numerical experiment 2 : Convergence path for $k-a$ search from initial point $g$ using a Polar objective function in conjunction with Polak 2 and Powell optimization methods. 


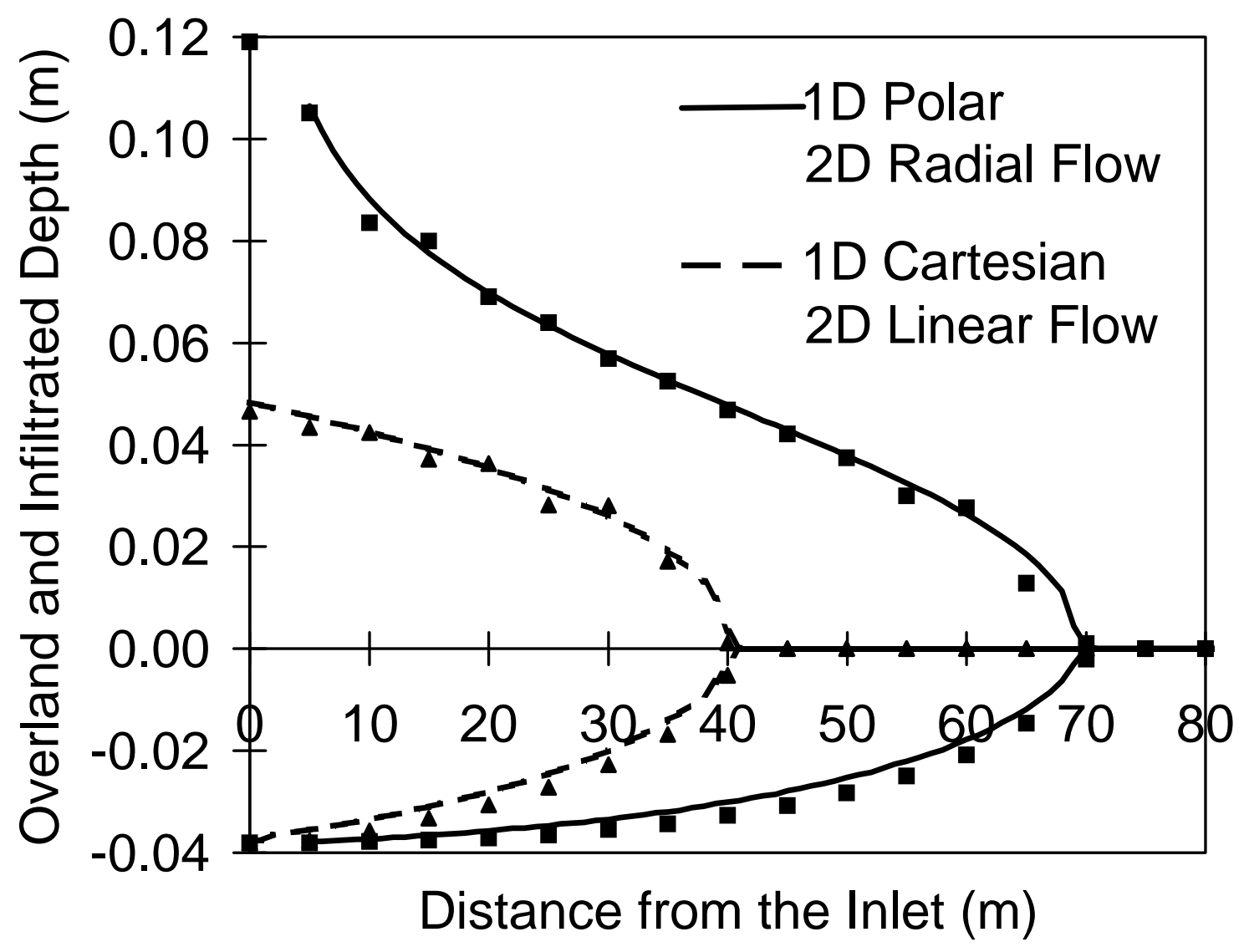

Figure 1 


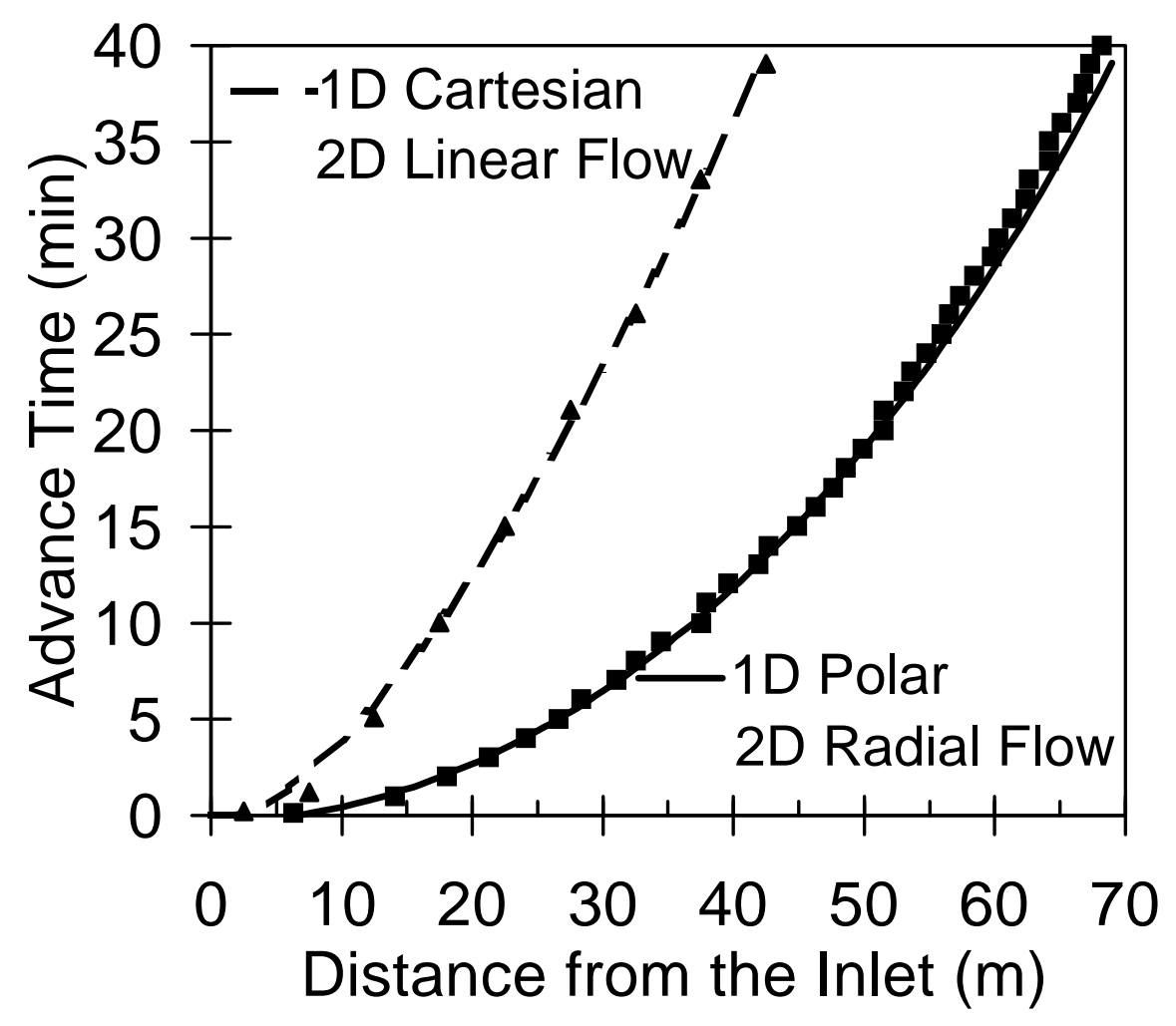

Figure 2 


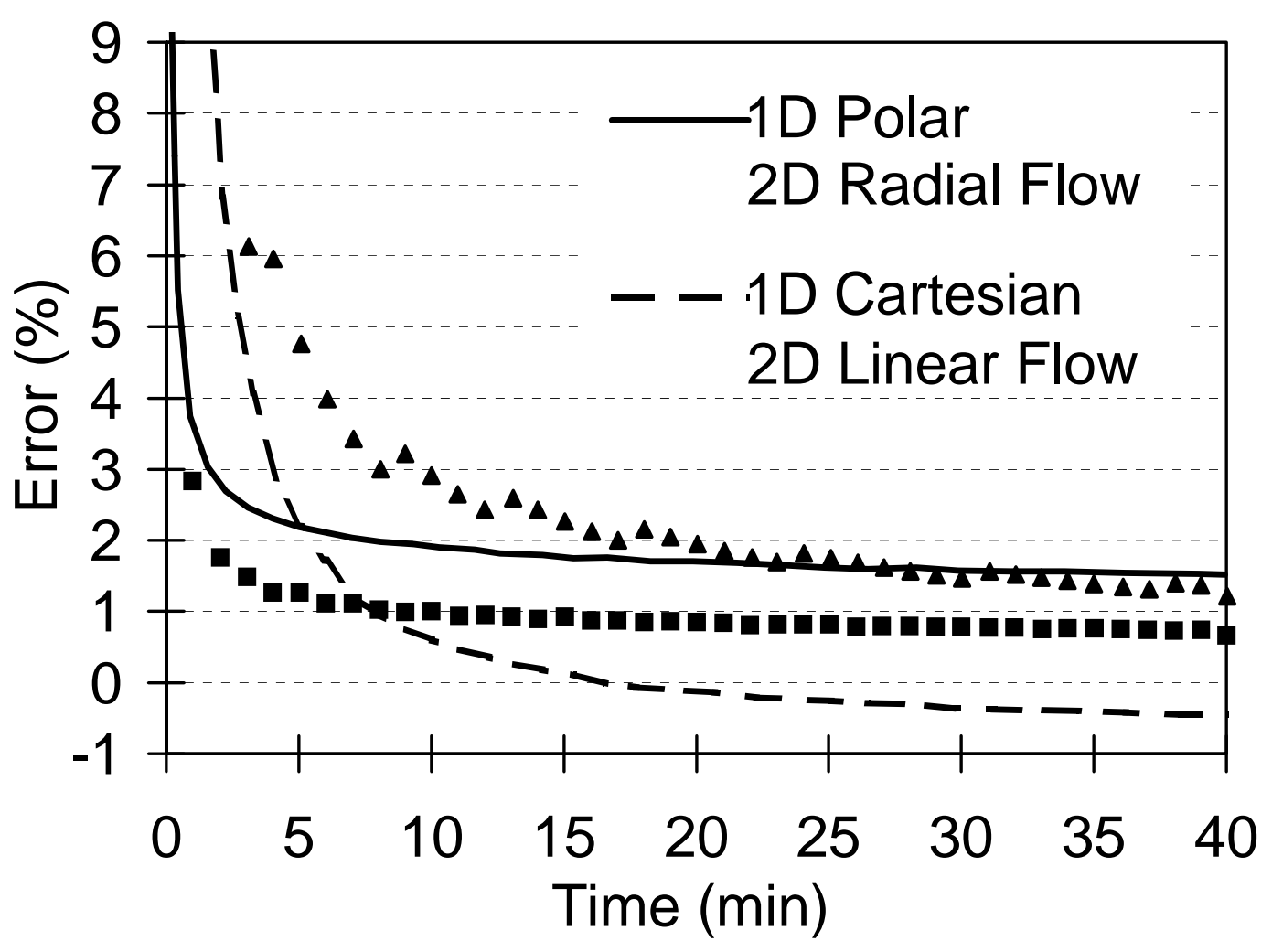

Figure 3 


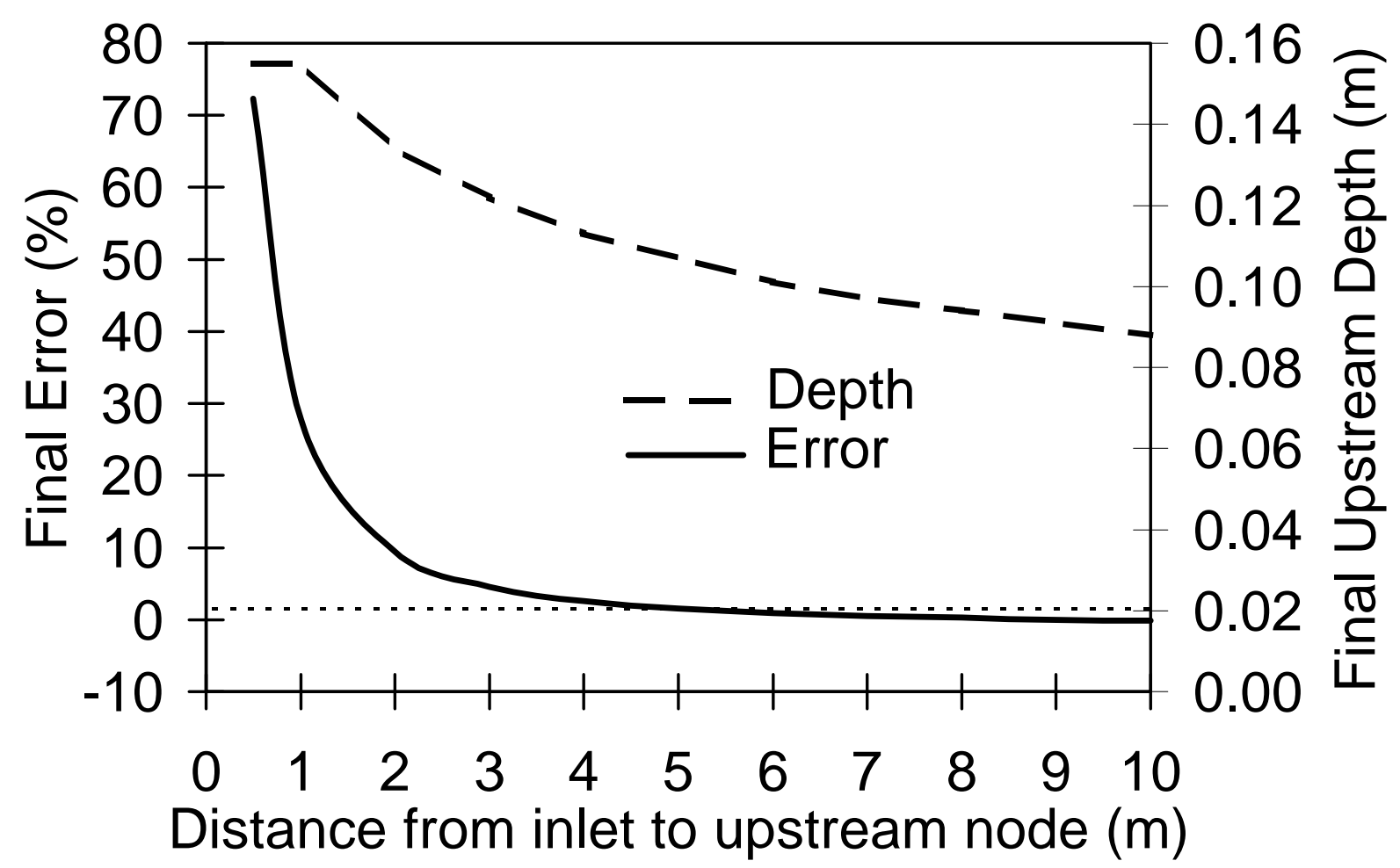

Figure 4 


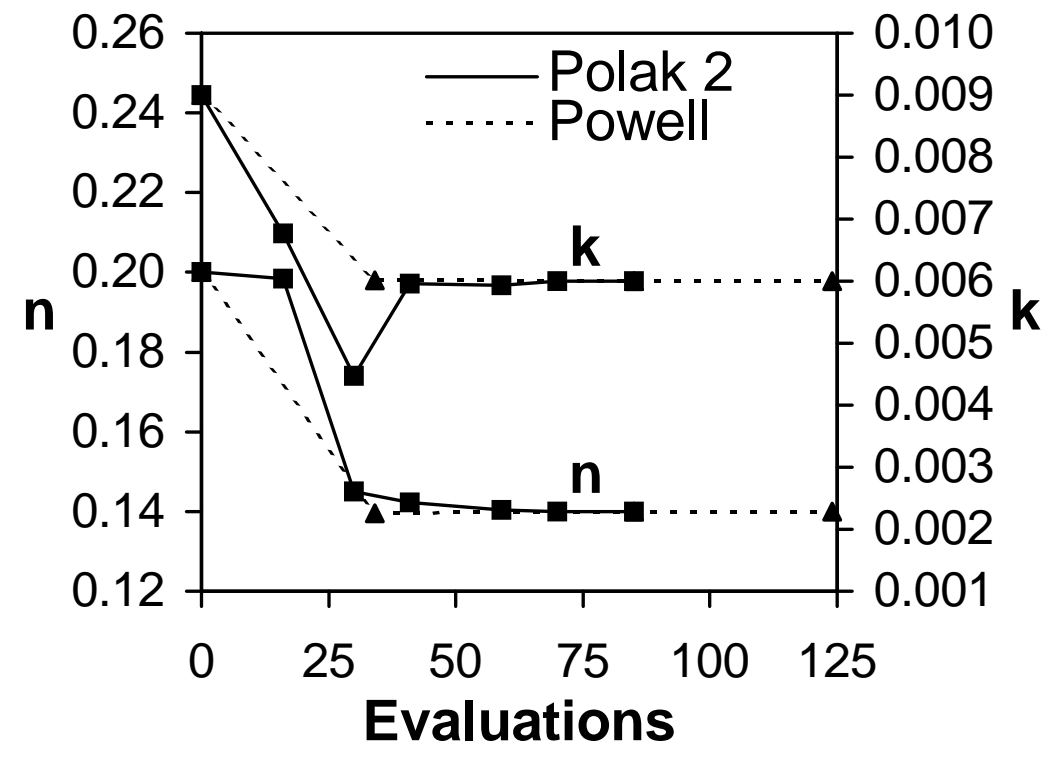

Figure 6 


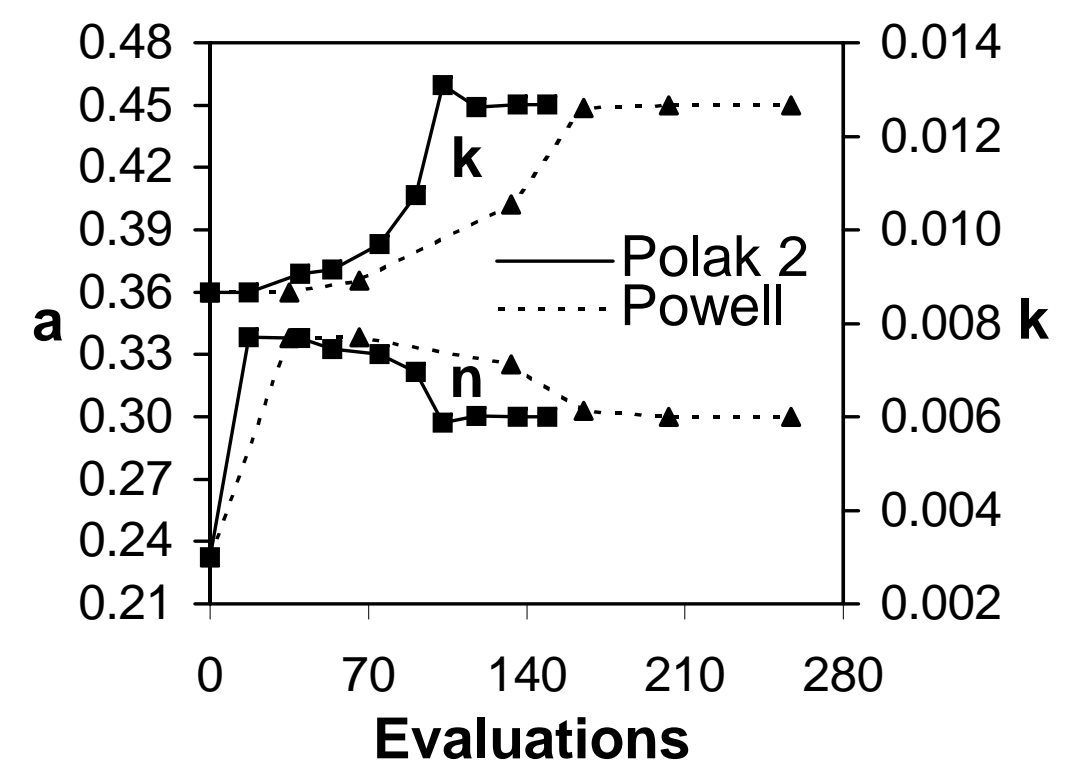

Figure 7 
Table 1

\begin{tabular}{|c|c|c|c|c|c|c|c|}
\hline \multicolumn{4}{|c|}{$\mathrm{n}$ and $\mathrm{k}$ estimation } & \multicolumn{4}{|c|}{$\mathrm{k}$ and a estimation } \\
\hline $\begin{array}{l}\text { Point } \\
\text { (1) }\end{array}$ & $\begin{array}{c}n \\
\text { (2) }\end{array}$ & $\mathrm{k}\left(\mathrm{m} \mathrm{min}^{-\mathrm{a}}\right)$ & $\begin{array}{c}a \\
(4)\end{array}$ & $\begin{array}{l}\text { Point } \\
\text { (5) }\end{array}$ & $\begin{array}{c}n \\
(6)\end{array}$ & $\begin{array}{c}\mathrm{k}\left(\mathrm{m} \min ^{-\mathrm{a}}\right) \\
(7)\end{array}$ & $\begin{array}{c}\mathrm{a} \\
(8)\end{array}$ \\
\hline$a$ & 0.08 & 0.009 & 0.50 & $\mathrm{e}$ & 0.14 & 0.003 & 0.54 \\
\hline b & 0.20 & 0.009 & 0.50 & $\mathrm{f}$ & 0.14 & 0.009 & 0.54 \\
\hline c & 0.08 & 0.003 & 0.50 & g & 0.14 & 0.003 & 0.36 \\
\hline d & 0.20 & 0.003 & 0.50 & $\mathrm{~h}$ & 0.14 & 0.009 & 0.36 \\
\hline Solution & 0.14 & 0.006 & 0.50 & Solution & 0.14 & 0.006 & 0.45 \\
\hline
\end{tabular}




\begin{tabular}{|c|c|c|c|c|c|c|c|c|c|c|}
\hline \multirow{2}{*}{$\begin{array}{l}\text { Objective } \\
\text { Function } \\
\text { (1) }\end{array}$} & \multirow{2}{*}{$\begin{array}{c}\text { Initial } \\
\text { point } \\
(2) \\
\end{array}$} & \multicolumn{3}{|c|}{ Objective Function Evaluations } & \multicolumn{3}{|c|}{ Iterations } & \multicolumn{3}{|c|}{ Evaluations per Iteration } \\
\hline & & $\begin{array}{c}\text { Polak } 1 \\
(3)\end{array}$ & $\begin{array}{c}\text { Polak } 2 \\
(4)\end{array}$ & $\begin{array}{c}\text { Powell } \\
(5)\end{array}$ & $\begin{array}{c}\text { Polak } 1 \\
(6)\end{array}$ & $\begin{array}{c}\text { Polak } 2 \\
(7)\end{array}$ & $\begin{array}{c}\text { Powell } \\
(8)\end{array}$ & $\begin{array}{c}\text { Polak } 1 \\
(9)\end{array}$ & $\begin{array}{c}\text { Polak } 2 \\
(10)\end{array}$ & $\begin{array}{c}\text { Powell } \\
(11)\end{array}$ \\
\hline \multirow{5}{*}{ Cartesian } & $\mathrm{a}$ & 54 & 61 & 129 & 5 & 4 & 3 & 10.8 & 15.3 & 43.0 \\
\hline & $\mathrm{b}$ & 163 & 110 & 167 & 13 & 9 & 4 & 12.5 & 12.2 & 41.8 \\
\hline & c & 92 & 100 & 168 & 8 & 7 & 4 & 11.5 & 14.3 & 42.0 \\
\hline & d & - & 132 & 203 & - & 9 & 4 & - & 14.7 & 50.8 \\
\hline & Average & 103 & 101 & 167 & 8.7 & 7.3 & 3.8 & 11.6 & 14.1 & 44.4 \\
\hline \multirow{5}{*}{ Polar } & $\mathrm{a}$ & 68 & 103 & 81 & 6 & 8 & 2 & 11.3 & 12.9 & 40.5 \\
\hline & $\mathrm{b}$ & 50 & 85 & 124 & 5 & 6 & 3 & 10.0 & 14.2 & 41.3 \\
\hline & c & 60 & 70 & 129 & 6 & 6 & 3 & 10.0 & 11.7 & 43.0 \\
\hline & $\mathrm{d}$ & 45 & 115 & 105 & 5 & 9 & 3 & 9.0 & 12.8 & 35.0 \\
\hline & Average & 56 & 93 & 110 & 5.5 & 7.3 & 2.8 & 10.1 & 12.9 & 40.0 \\
\hline \multirow{5}{*}{$\begin{array}{c}\text { Weighted } \\
\text { Polar }\end{array}$} & $\mathrm{a}$ & - & 107 & 186 & - & 7 & 4 & - & 15.3 & 46.5 \\
\hline & b & - & 105 & 116 & - & 7 & 3 & - & 15.0 & 38.7 \\
\hline & c & 50 & 86 & 122 & 5 & 6 & 3 & 10.0 & 14.3 & 40.7 \\
\hline & $\mathrm{d}$ & 89 & 79 & 197 & 9 & 6 & 4 & 9.9 & 13.2 & 49.3 \\
\hline & Average & 70 & 94 & 155 & 7.0 & 6.5 & 3.5 & 9.9 & 14.4 & 43.8 \\
\hline
\end{tabular}


Table 3

\begin{tabular}{|c|c|c|c|c|c|c|c|c|c|c|}
\hline \multirow{2}{*}{$\begin{array}{l}\text { Objective } \\
\text { Function } \\
\text { (1) }\end{array}$} & \multirow{2}{*}{$\begin{array}{c}\text { Initial } \\
\text { point } \\
(2)\end{array}$} & \multicolumn{3}{|c|}{ Objective Function Evaluations } & \multicolumn{3}{|c|}{ Iterations } & \multicolumn{3}{|c|}{ Evaluations per Iteration } \\
\hline & & $\begin{array}{c}\text { Polak } 1 \\
(3)\end{array}$ & $\begin{array}{c}\text { Polak } 2 \\
(4)\end{array}$ & $\begin{array}{c}\text { Powell } \\
(5) \\
\end{array}$ & $\begin{array}{c}\text { Polak } 1 \\
(6) \\
\end{array}$ & $\begin{array}{c}\text { Polak } 2 \\
(7)\end{array}$ & $\begin{array}{c}\text { Powell } \\
(8) \\
\end{array}$ & $\begin{array}{c}\text { Polak } 1 \\
(9)\end{array}$ & $\begin{array}{c}\text { Polak } 2 \\
(10) \\
\end{array}$ & $\begin{array}{c}\text { Powell } \\
(11) \\
\end{array}$ \\
\hline \multirow{5}{*}{ Cartesian } & $\mathrm{e}$ & - & - & 304 & - & - & 6 & - & - & 50.7 \\
\hline & $\mathrm{f}$ & - & - & - & - & - & - & - & - & - \\
\hline & g & - & - & - & - & - & - & - & - & - \\
\hline & $\mathrm{h}$ & - & - & 369 & - & - & 7 & - & - & 52.7 \\
\hline & Average & - & - & 337 & - & - & 6.5 & - & - & 51.7 \\
\hline \multirow{5}{*}{ Polar } & e & - & - & 281 & - & - & 6 & - & - & 46.8 \\
\hline & $\mathrm{f}$ & - & - & 237 & - & - & 5 & - & - & 47.4 \\
\hline & g & - & 149 & 257 & - & 9 & 6 & - & 16.6 & 42.8 \\
\hline & $\mathrm{h}$ & - & - & 353 & - & - & 7 & - & - & 50.4 \\
\hline & Average & - & 149 & 282 & - & 9.0 & 6.0 & - & 16.6 & 46.9 \\
\hline \multirow{5}{*}{$\begin{array}{c}\text { Weighted } \\
\text { Polar }\end{array}$} & $\mathrm{e}$ & - & - & 169 & $\overline{-}$ & - & 4 & - & - & 42.3 \\
\hline & $\mathrm{f}$ & - & - & 116 & - & - & 3 & - & - & 38.7 \\
\hline & g & - & - & - & - & - & - & - & - & - \\
\hline & $\mathrm{h}$ & - & - & - & - & - & - & - & - & - \\
\hline & Average & - & - & 143 & - & - & 3.5 & - & - & 40.5 \\
\hline
\end{tabular}

